\title{
Risk Factors and Impact of Diagnostic Delay in Patients with Inflammatory Bowel Disease in Bangladesh
}

\author{
Chanchal Kumar Ghosh*, S. M. Ali Hasan, Md Abdur Rahim Miah \\ Department of Gastroenterology, Bangabandhu Sheikh Mujib Medical University, Dhaka, Bangladesh \\ Email address: \\ dr.chanchalghosh@gmail.com (C. K. Ghosh) \\ ${ }^{*}$ Corresponding author

\section{To cite this article:} \\ Chanchal Kumar Ghosh, S. M. Ali Hasan, Md Abdur Rahim Miah. Risk Factors and Impact of Diagnostic Delay in Patients with \\ Inflammatory Bowel Disease in Bangladesh. American Journal of Internal Medicine. Vol. 8, No. 6, 2020, pp. $258-262$. \\ doi: 10.11648/j.ajim.20200806.13
}

Received: October 14, 2020; Accepted: October 23, 2020; Published: October 30, 2020

\begin{abstract}
Background and Aims: A delay in the diagnosis of inflammatory bowel disease (IBD) is a risk of developing complications and surgery. This study was done to evaluate the factors and impact of diagnostic delay on IBD patients in Bangladesh. Methods: This cross-sectional study was carried out in the Department of Gastroenterology of a tertiary care center in Bangladesh. Diagnostic delay was defined as the period from symptom onset to diagnosis of IBD. Results: Of the total 112 IBD patients 50 (44.6\%) had Crohn's disease CD and $62(55.4 \%)$ had ulcerative colitis (UC). Males (67.9\%) were predominant in the study. The median diagnostic delay was longer for patients with CD compared with patients with UC (median 24 versus 12 months; P-value 0.025). Rectal bleeding as presenting feature and male gender were negatively and positively associated with the longer diagnostic delay of IBD respectively (P-value $<0.05)$. Of the patients with CD $14(28 \%)$ had a history of IBD-related surgery and $7(14 \%)$ had a history of perianal fistula. The presence of intestinal strictures, surgery, and perianal fistula at the time of diagnosis was significantly associated with long diagnostic delay for $\mathrm{CD}$. Conclusion: Absence of rectal bleeding as presenting symptoms and also the male gender were the significant factors related to the longer diagnostic delay of IBD in our study. Long diagnostic delay is associated with an increased rate of complications in IBD, especially in CD.
\end{abstract}

Keywords: Diagnostic Delay, Inflammatory Bowel Disease (IBD), Crohn's Disease (CD), Ulcerative Colitis (UC), Referral Delay

\section{Introduction}

Inflammatory bowel diseases (IBD), namely Crohn's disease (CD) and ulcerative colitis (UC) are a group of chronic idiopathic disorder with the relapsing and remitting course. The highest incidence and prevalence are in Western populations. However, recent studies from Asian and developing countries indicate an increasing incidence of time trends [1]. The outcome of IBD cases mostly depends on early diagnosis and timely intervention. Early initiation of immunosuppressive and/or biological agents has been reported to be associated with better outcomes [24]. Delay in diagnosis is associated with delayed therapy which causes continued disease activity, prolonged suffering, and complications requiring early surgery $[5,6]$. The diagnosis of IBD is challenging and usually delayed due to a broad variety of presenting symptoms, which are nonspecific and misleading for gastrointestinal infections or functional disorders $[7,8]$. A diagnostic delay of several months to years is common in IBD, especially in CD [9-17]. Factors associated with diagnostic delay are incompletely understood and many have conflicting results, such as young age at diagnosis, active smoking, socioeconomic factors, and ileal location [9-17]. No published data regarding the diagnostic delay in Bangladeshi IBD patients have been reported so far. Therefore, this study aimed to evaluate the diagnostic delay and its associated factors, and the impact of it on IBD patients at a tertiary care center in Bangladesh. 


\section{Methods}

\subsection{Study Population and Data Collection}

It is a cross-sectional study at a tertiary care center in Bangladesh. Patients were recruited between September 2018 and September 2019. Adult IBD patients ( $\geq 18$ years of age) with an established diagnosis based on clinical, endoscopic, histological, and radiological criteria according to the European Crohn's and Colitis Organization (ECCO) guidelines [18, 19] attending dedicated IBD clinic of Gastroenterology were asked to participate in the study. The data were collected prospectively using a predesigned questionnaire, which included items concerning demographic characteristics (age, gender, educational level, household income, residential area, and smoking habits, diagnostic delay and referral delay to the specialist) and IBD-related data (e.g. Disease types, Predominant presenting complaints, complications).

\subsection{Definitions}

Total diagnostic delay was defined as the time from the onset of symptoms related to IBD to the final diagnosis by gastroenterologists.

\subsection{Statistical Analysis}

The data were analyzed by using Statistical Package for Social Studies (SPSS 25; IBM Corp., New York, NY, USA). Nonparametric data were expressed as median \pm interquartile range (IQR) and categorical data were expressed as frequency and percentages. Spearman Rho correlation coefficient was used to see the correlation. Risk factors and the rate of complications were assessed with long ( $>75$ th percentile) diagnostic delays. A P value $<0.05$ was considered statistically significant.

\subsection{IRB Approval}

We conducted this study in compliance with the principles of the Declaration of Helsinki. The study's protocol was reviewed and approved by the Institutional Review Board of the University. Written informed consent was obtained.

\section{Results}

The characteristics of the study population are summarized in Table 1. A total of 112 IBD patients were enrolled from a dedicated IBD clinic. Of the patients $50(44.6 \%)$ had CD and $62(55.4 \%)$ had UC. The mean age was $35.43 \pm 11.87$ years. Males $(67.9 \%)$ were predominant in both patients with CD (78\%) and UC (59.7\%). Of the patients with CD 14 (28\%) had a history of IBD-related surgery and 7 (14\%) had a history of perianal fistula. More patients with $\mathrm{CD}$ were smokers than with UC (18\% vs. $4.8 \%)$. Most of the patients had secondary and higher secondary level education. The majority had a household income of up to $120 \$$ per month, nearly half of the patients lived in rural areas. Only 7 (6.3\%) of IBD patients directly consulted to a gastroenterologist and $65(58 \%)$ of IBD patients were referred to a gastroenterologist by other physicians after a median referral delay of 12 months (IQR 5.5-24 months). The referral delay was positively correlated with diagnostic delay (correlation coefficient, $\mathrm{r}=0.87$ ).

Table 1. Characteristics of study population ( $n=112)$.

\begin{tabular}{|c|c|c|c|c|}
\hline \multirow{2}{*}{ Characteristic } & \multicolumn{2}{|l|}{ Disease type } & \multirow{2}{*}{ Total IBD $(n=112)$} & \multirow{2}{*}{ P-value } \\
\hline & CD $(n=50)$ & $\mathrm{UC}(\mathrm{n}=62)$ & & \\
\hline & $35.08 \pm 12.78$ & $35.71 \pm 11.18$ & $35.43 \pm 11.87$ & 0.782 \\
\hline Gender & & & & \\
\hline Male & $39(78.0)$ & $37(59.7)$ & $76(67.9)$ & \multirow{2}{*}{0.044} \\
\hline Female & $11(22.0)$ & $25(40.3)$ & $36(32.1)$ & \\
\hline Residence & & & & \multirow{4}{*}{0.376} \\
\hline Rural & $20(40.0)$ & $33(53.2)$ & $53(47.3)$ & \\
\hline Urban & $13(26.0)$ & $13(21.0)$ & $26(23.2)$ & \\
\hline Semi-urban & $17(34.0)$ & $16(25.8)$ & $33(29.5)$ & \\
\hline Educational level & & & & \multirow{4}{*}{0.424} \\
\hline Primary and below & $12(24.0)$ & $16(25.8)$ & $28(25.0)$ & \\
\hline Secondary and higher secondary & $24(48.0)$ & $35(56.5)$ & $59(52.7)$ & \\
\hline Graduate and above & $14(28.0)$ & $11(17.7)$ & $25(22.3)$ & \\
\hline Family history of IBD & $2(4.0)$ & $8(12.9)$ & $10(8.9)$ & 0.181 \\
\hline \multicolumn{4}{|l|}{ Monthly family income } & \multirow{4}{*}{0.059} \\
\hline$<120 \$$ & $33(66.0)$ & $27(44.3)$ & $60(54.1)$ & \\
\hline \multirow{3}{*}{$\begin{array}{l}120-350 \$ \\
>350 \$\end{array}$} & $12(24.0)$ & $27(44.3)$ & $39(35.1)$ & \\
\hline & $5(10.0)$ & $7(11.5)$ & $12(10.8)$ & \\
\hline & & & & \\
\hline Smoker & $9(18.0)$ & $3(4.8)$ & $12(10.7)$ & \multirow{3}{*}{0.081} \\
\hline Former smoker & $6(12.0)$ & $8(12.9)$ & $14(12.5)$ & \\
\hline Non smoker & $35(70.0)$ & $51(82.3)$ & $86(76.8)$ & \\
\hline \multirow{4}{*}{$\begin{array}{l}\text { History of NSAID use } \\
\text { History of Anti tubercular therapy } \\
\text { Diagnostic Delay in months (Median } \pm \mathrm{IQR} \text { ) } \\
\text { Predominant presenting complaints }\end{array}$} & $20(40.0)$ & $10(16.1)$ & $30(26.8)$ & \multirow{4}{*}{$\begin{array}{l}0.006 \\
<0.0001 \\
0.025\end{array}$} \\
\hline & $23(46.0)$ & $0(0.0)$ & $23(20.5)$ & \\
\hline & $24(9.8-48)$ & $12(6-24)$ & $18(7-36)$ & \\
\hline & & & & \\
\hline Diarrhoea & $27(37.0)$ & $46(63.0)$ & $73(100.0)$ & 0.026 \\
\hline
\end{tabular}




\begin{tabular}{|c|c|c|c|c|}
\hline \multirow{2}{*}{ Characteristic } & \multicolumn{2}{|l|}{ Disease type } & \multirow{2}{*}{ Total IBD $(n=112)$} & \multirow{2}{*}{ P-value } \\
\hline & $\mathrm{CD}(\mathrm{n}=\mathbf{5 0})$ & $\mathrm{UC}(\mathrm{n}=62)$ & & \\
\hline Rectal bleeding & $14(21.9)$ & $50(78.1)$ & $64(100.0)$ & $<0.0001$ \\
\hline Abdominal pain & $43(55.1)$ & $35(43.2)$ & $78(100.0)$ & 0.001 \\
\hline \multicolumn{5}{|l|}{ Complications } \\
\hline Surgery & $14(70.0)$ & $6(30.0)$ & $20(100.0)$ & 0.012 \\
\hline Stenosis & $10(90.9)$ & $1(9.1)$ & $11(100.0)$ & 0.002 \\
\hline Perianal fistula & $7(87.5)$ & $1(12.5)$ & $8(100.0)$ & 0.021 \\
\hline \multicolumn{5}{|l|}{ First attended physician } \\
\hline GI specialist & $4(8.0)$ & $3(4.8)$ & $7(6.3)$ & \\
\hline Non-GI physician & $31(62.0)$ & $33(53.2)$ & $64(57.1)$ & 0.388 \\
\hline Non registered practitioner & $15(30.0)$ & $26(41.9)$ & $41(36.6)$ & \\
\hline Referred to GI specialist before diagnosis & $27(54.0)$ & $38(61.3)$ & $65(58.0)$ & 0.437 \\
\hline Referral delay to GI specialist (months, Median \pm IQR) & $12(5.8-24)$ & $12(5-24)$ & $12(5.5-24)$ & 0.641 \\
\hline
\end{tabular}

Values are presented as mean $\pm \mathrm{SD}$, Median $\pm \mathrm{IQR}$, number (\%). IBD, Inflammatory Bowel Disease; CD, Crohn's Disease; UC, Ulcerative Colitis; IQR, Inter Quartile Range.

Table 2. Factors associated with a long diagnostic delay in overall study population $(n=112)$.

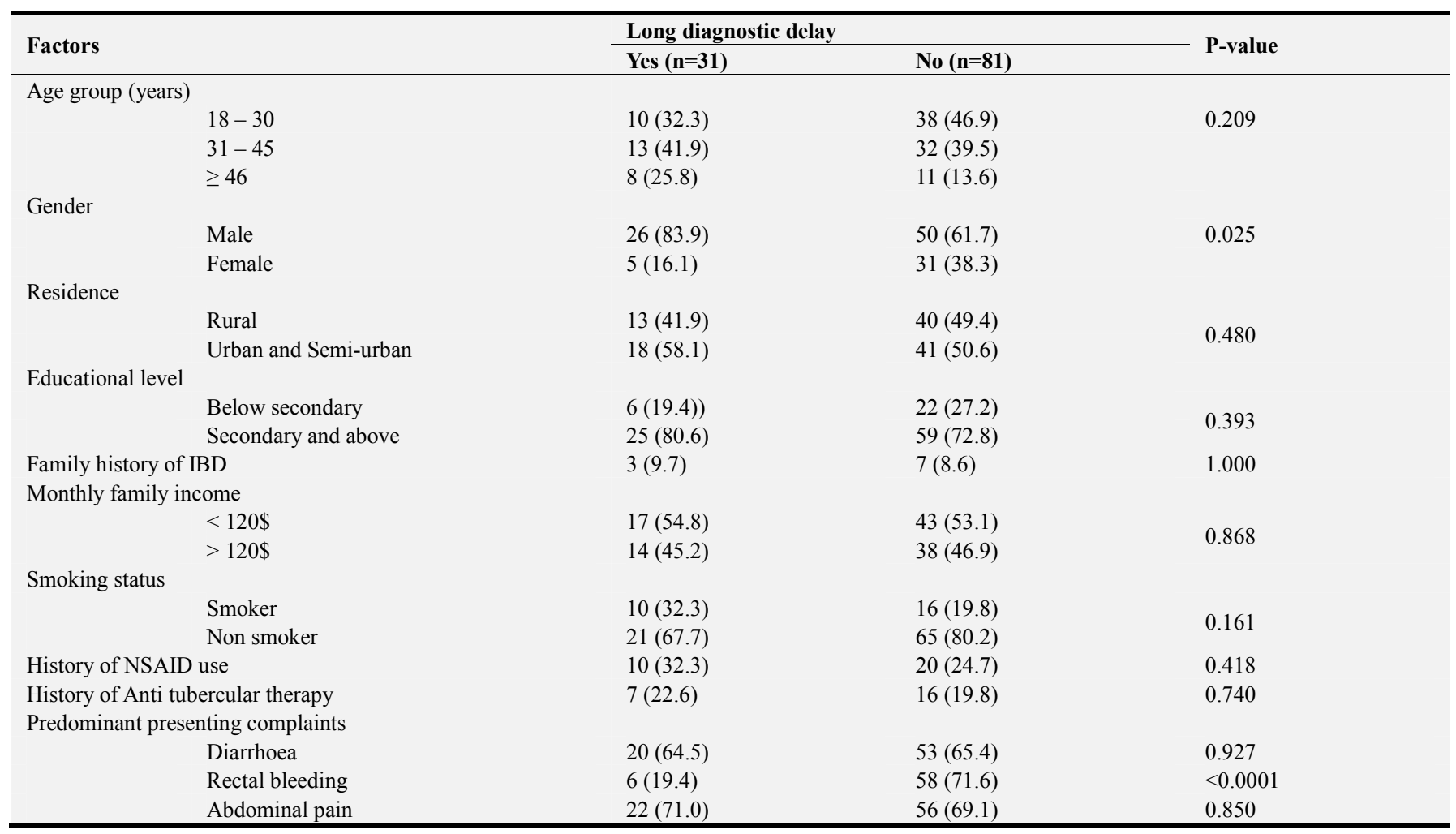

Values are presented as number (\%). Long diagnostic delay for IBD $\geq 36$ months (3rd quartile of diagnostic intervals).

Table 3. Crohn's disease-related complications in the study population according to the diagnostic delay $(n=50)$.

\begin{tabular}{llll}
\hline \multirow{2}{*}{ Complications (CD) } & Long diagnostic delay & & \\
\cline { 2 - 3 } & Yes $(\mathbf{n}=\mathbf{1 3})$ & No $(\mathbf{n}=\mathbf{3 7})$ & \\
\hline Surgery & $9(64.3)$ & $5(35.7)$ & $<0.0001$ \\
Stenosis & $6(54.5)$ & $5(45.5)$ & 0.023 \\
Perianal fistula & $6(85.7)$ & $1(14.3)$ & 0.001 \\
\hline
\end{tabular}

Values are presented as number (\%). Long diagnostic delay for Crohn's disease $\geq 48$ months (3rd quartile of diagnostic intervals).

\subsection{Diagnostic Delay}

The median diagnostic delay for the total IBD patients was 18 months (Inter Quartile Range, IQR 7-36 months). The median diagnostic delay in patients with $\mathrm{CD}$ was 24 months (IQR 9.75-48 months) and in patients with UC 12 months
(IQR 6-24 months) $(\mathrm{p}<0.025)$. According to the division standard of the Swiss inflammatory bowel disease study [9], the diagnostic interval was defined as the diagnostic delay. Long diagnostic delay was more than 36 months and 48 months for total IBD patients and patients with $\mathrm{CD}$ respectively in our study (third quartile of diagnostic intervals). 


\subsection{Factors Influencing Diagnostic Delay}

All IBD patients were stratified into 2 groups based on a long diagnostic delay of 36 months. Among examined factors, predominant presenting symptom with rectal bleeding was associated with a shorter diagnostic delay ( $p$ value $<0.0001)$. By contrast, male patients had a longer time to diagnosis compared with the female (p-value 0.025). Other factors like age, living area, level of education, household income, smoking status, NSAIDs use, history of getting antitubercular medication, family history of IBD did not seem to be associated with diagnostic delay (Table 2).

\subsection{Complications Associated with Long Diagnostic Delay in $C D$}

IBD-related complications by the time of diagnosis among patients with $\mathrm{CD}$ were stratified by third quartiles of time to diagnosis and are summarized in Table 3 . The presence of intestinal strictures, surgery, and perianal fistula at the time of diagnosis was significantly associated with long diagnostic delay for CD.

\section{Discussion}

Identifying risk factors of diagnostic delay is a demanding issue in case of chronic disabling and progressive conditions. Only a few studies have reported the issue of diagnostic delay. The length of diagnostic delay and its associated factors, and the impact of it on IBD patients vary widely. To our knowledge, this is the first study on diagnostic delay in patients with IBD in Bangladeshi. We found that the diagnostic delay was significantly longer in $C D$ than in UC which is a similar finding with the other studies [9-17]. The median diagnostic delay was 24 months for $\mathrm{CD}$ and 18 months for UC. Our study population had a longer diagnostic delay than the diagnostic delay found in other studies. This finding might be due to the majority of our IBD patients were first attended to general practitioners and non-registered local practitioners, and they were referred to a specialist after a median referral delay of 12 months. The initial presenting features seem to be the main drivers for diagnostic delay. For example, rectal bleeding is an alarming symptom that causes awareness of both patients and physicians to investigate and usually leads to early diagnosis. This is probably the main reason for the earlier diagnosis in UC and also in $\mathrm{CD}$ with presenting features of rectal bleeding. In this study, rectal bleeding was the chief presenting complaint in $78.1 \%$ of patients with UC, which may explain the earlier diagnosis of UC. Patients with CD presented with rectal bleeding were also diagnosed earlier and had fewer complications at diagnosis [5]. In this study male patients with IBD were more commonly associated with long diagnostic delay compared to females, (34.2\% vs. $13.9 \%)$. This observation might be due to the predominance of male patients in this study. Studies have reported that $\mathrm{CD}$ progresses to stricturing and/or penetrating disease over time [20, 21]. We found that CD patients with a long diagnostic delay were associated with an increased rate of complications at diagnosis which is consistent with other studies [5, 10-15, 17]. The relationship of complications at diagnosis with a long diagnostic delay indicates earlier diagnosis might have an impact on disease outcomes. In this study, there was also considerable physician-related delay, especially among general practitioners and non-registered practitioners, in detecting the nature of the disease and also referring to the GI specialist for evaluation. This emphasizes the necessity of development of awareness about the disease among physicians, especially primary health care providers [22].

This is the first study evaluating the diagnostic delay of IBD in Bangladeshi patients. Nevertheless, limitations exist in this study: due to the small number of patients recruited from a single center, our results may not completely reflect the actual risk factors and impacts of diagnostic delay.

\section{Conclusion}

Diagnostic delay is associated with an increased rate of complications in IBD. The observations from this study can provide support for efforts to reduce delaying of diagnosis in patients with IBD. We also need to arouse the concern of the general people and primary health care providers about avoiding such delays, which can contribute to a worse prognosis. The prognostic importance of diagnostic delay should be emphasized and appropriate measures should be implemented to reduce this delay.

\section{References}

[1] $\mathrm{Ng} \mathrm{SC}$, Shi HY, Hamidi N, et al. Worldwide incidence and prevalence of inflammatory bowel disease in the 21st century: a systematic review of population-based studies. Lancet. 2018; 390 (10114): 2769-2778.

[2] D'Haens G, Baert F, van Assche G, et al. Early combined immunosuppression or conventional management in patients with newly diagnosed Crohn's disease: an open randomised trial. Lancet. 2008; 371 (9613): 660-667.

[3] Schreiber S, Colombel JF, Bloomfield R, et al. Increased response and remission rates in short-duration Crohn's disease with subcutaneous certolizumab pegol: an analysis of PRECiSE 2 randomized maintenance trial data. Am J Gastroenterol. 2010; 105 (7): 1574-1582.

[4] Khanna R, Bressler B, Levesque BG, et al. Early combined immunosuppression for the management of Crohn's disease (REACT): a cluster randomised controlled trial. Lancet. 2015; 386 (10006): 1825-1834.

[5] Nguyen VQ, Jiang D, Hoffman SN, et al. Impact of Diagnostic Delay and Associated Factors on Clinical Outcomes in a U.S. Inflammatory Bowel Disease Cohort. Inflamm Bowel Dis. 2017; 23 (10): 1825-1831.

[6] Nahon S, Lahmek P, Paupard T, et al. Diagnostic Delay Is Associated with a Greater Risk of Early Surgery in a French Cohort of Crohn's Disease Patients. Dig Dis Sci. 2016; 61 (11): 3278-3284. 
[7] Danese S, Fiorino G, Mary JY, et al. Development of Red Flags Index for Early Referral of Adults with Symptoms and Signs Suggestive of Crohn's Disease: An IOIBD Initiative. $J$ Crohns Colitis. 2015; 9 (8): 601-606.

[8] Burgmann T, Clara I, Graff L, et al. The Manitoba Inflammatory Bowel Disease Cohort Study: prolonged symptoms before diagnosis--how much is irritable bowel syndrome? Clin Gastroenterol Hepatol. 2006; 4 (5): 614-620.

[9] Vavricka SR, Spigaglia SM, Rogler G, et al. Systematic evaluation of risk factors for diagnostic delay in inflammatory bowel disease. Inflamm Bowel Dis. 2012; 18 (3): 496-505.

[10] Schoepfer AM, Dehlavi MA, Fournier N, et al. Diagnostic delay in Crohn's disease is associated with a complicated disease course and increased operation rate. $\mathrm{Am} J$ Gastroenterol. 2013; 108 (11): 1744-1753; quiz 1754.

[11] Nahon S, Lahmek P, Lesgourgues B, et al. Diagnostic delay in a French cohort of Crohn's disease patients. J Crohns Colitis. 2014; 8 (9): 964-969.

[12] Li Y, Ren J, Wang G, et al. Diagnostic delay in Crohn's disease is associated with increased rate of abdominal surgery: A retrospective study in Chinese patients. Dig Liver Dis. 2015; 47 (7): 544-548.

[13] Pellino G, Sciaudone G, Selvaggi F, Riegler G. Delayed diagnosis is influenced by the clinical pattern of Crohn's disease and affects treatment outcomes and quality of life in the long term: a cross-sectional study of 361 patients in Southern Italy. Eur J Gastroenterol Hepatol. 2015; 27 (2): 175-181.

[14] Moon CM, Jung SA, Kim SE, et al. Clinical Factors and Disease Course Related to Diagnostic Delay in Korean Crohn's Disease Patients: Results from the CONNECT Study. PLoS One. 2015; 10 (12): e0144390.
[15] Lee DW, Koo JS, Choe JW, et al. Diagnostic delay in inflammatory bowel disease increases the risk of intestinal surgery. World J Gastroenterol. 2017; 23 (35): 6474-6481.

[16] Cantoro L, Di Sabatino A, Papi C, et al. The Time Course of Diagnostic Delay in Inflammatory Bowel Disease Over the Last Sixty Years: An Italian Multicentre Study. J Crohns Colitis. 2017; 11 (8): 975-980.

[17] Zaharie R, Tantau A, Zaharie F, et al. Diagnostic Delay in Romanian Patients with Inflammatory Bowel Disease: Risk Factors and Impact on the Disease Course and Need for Surgery. J Crohns Colitis. 2016; 10 (3): 306-314.

[18] Gomollón F, Dignass A, Annese V, et al. 3rd European Evidence-based Consensus on the Diagnosis and Management of Crohn's Disease 2016: Part 1: Diagnosis and Medical Management. J Crohns Colitis. 2017; 11 (1): 3-25.

[19] Magro F, Gionchetti P, Eliakim R, et al. Third European Evidence-based Consensus on Diagnosis and Management of Ulcerative Colitis. Part 1: Definitions, Diagnosis, Extraintestinal Manifestations, Pregnancy, Cancer Surveillance, Surgery, and Ileo-anal Pouch Disorders. J Crohns Colitis. 2017; 11 (6): 649-670.

[20] Cosnes J, Gower-Rousseau C, Seksik P, Cortot A. Epidemiology and natural history of inflammatory bowel diseases. Gastroenterology. 2011; 140 (6): 1785-1794.

[21] Louis E, Collard A, Oger AF, Degroote E, Aboul Nasr El Yafi FA, Belaiche J. Behaviour of Crohn's disease according to the Vienna classification: changing pattern over the course of the disease. Gut. 2001; 49 (6): 777-782.

[22] Benevento G, Avellini C, Terrosu G, Geraci M, Lodolo I, Sorrentino D. Diagnosis and assessment of Crohn's disease: the present and the future. Expert Rev Gastroenterol Hepatol. 2010; 4 (6): 757-766. 